\title{
Cine y resistencia: jóvenes, poderes y contrapoderes en la película La noche de los lápices
}

\author{
Nicolás Londoño-Osorio, Mg. ${ }^{a}$ \\ Cinde, Colombia \\ Carolina Hernández-Álvarez, Mg. ${ }^{\mathrm{b}}$ \\ Cinde, Colombia \\ Héctor Betancur-Giraldo, Mg. ${ }^{\mathrm{C}}$ \\ Escer, Colombia
}

nlondono@cinde.org.co

\section{Resumen (analítico)}

Las juventudes y movimientos estudiantiles en el mundo, especialmente en América Latina y Francia, retoman disertaciones sobre poder, contrapoder y resistencia desde la reflexión teórica de autores como Niklas Luhmann y Nicos Poulantzas. Aquellos señalan que los fenómenos de protesta y movimientos sociales de jóvenes son recreados con precisión en el cine en películas como La noche de los lápices (Olivera, 1986). Los autores, desde una mirada histórica y cinematográfica, evidencian las particularidades en los ejes detentores del poder (Estado y sociedad civil o jóvenes) que, medidos frente al Estado, experimentan significado, manifestación y abordaje en escenarios que cohabitan con la violencia. El artículo sugiere rutas para indagar el concepto de poder y estudios orientados en el cine sobre movimientos estudiantiles y juveniles en la actualidad.

\section{Palabras clave}

Cine, juventudes, movimiento estudiantil, poder.

\section{Thesauro}

Tesauro de Ciencias Sociales de la Unesco.

\section{Para citar este artículo}

Londoño-Osorio, N., Hernández-Álvarez, C., \& Betancur-Giraldo, H. (2021). Cine y resistencia: jóvenes, poderes y contrapoderes en la película $L a$ noche de los lápices. Revista Latinoamericana de Ciencias Sociales, Niñez y Juventud, 19(2), 1-24. https://dx.doi.org/10.11600/rlcsnj.19.2.4586

\section{Historial}

Recibido: 24.09 .2020

Aceptado: 30.11 .2020

Publicado: 14.04.2021

\section{Información artículo}

Artículo derivado de la investigación Los derechos humanos a través del cine, financiada por la Universidad Autónoma Latinoamericana, código 25000013, iniciada en enero de 2018, finalizada en diciembre de 2018. Área: sociología. Subárea: sociología. 


\title{
Cinema and resistance: Young people, powers and counter-powers in the movie «The Night of the Pencils»
}

\begin{abstract}
(analytical)
Youth and student movements around the world, especially in Latin America and France, are the subject of dissertations on power, counterpower and resistance through theoretical reflection by Niklas Luhmann and Nicos Poulantzas. These authors point out that the phenomena of protest and social movements of young people are accurately recreated in cinema in films such as "The Night of the Pencils" (Olivera, 1986). From an historical and cinematographic point of view, the authors highlight the specific depiction of holders of power contained in this film; the State and civil society or young people, and when measured against the State, experience meaning, manifestation and approach in scenarios that coexist with violence. The article ends with suggestions on routes for exploring the concept of power and film-oriented studies in relation to current student and youth movements.
\end{abstract}

Keywords

Cinema, youth, student movement, power.

\section{Cinema e resistência: Jovens, poderes e contrapoderes no filme A Noite dos Lápis}

\section{Resumo (analítico)}

As juventudes e os movimentos estudantis no mundo, especialmente na América Latina e França, retomam dissertações sobre poder, contrapoder e resistência, com base na reflexão teórica de autores como Niklas Luhmann e Nicos Poulantzas que assinalam que os fenômenos de protesto e movimentos sociais de jovens são recriados com precisão no cinema, em filmes como A noite dos lápis (Olivera, 1986). Os autores, a partir de um olhar histórico e cinematográfico, evidenciam as particularidades nos eixos detentores do poder: Estado e sociedade civil ou jovens, que medidos frente ao Estado, experimentam significado, manifestação e abordagem em cenários que coabitam com a violência. $\bigcirc$ artigo finaliza com sugestões sobre caminhos para questionar o conceito de poder e estudos orientados no cinema sobre movimentos estudantis e juvenis na atualidade.

Palavras-chave

Cinema, jovens, movimentos estudantis, poder.

Información autores

[a] Doctorando en Filosofía y Letras, Universidad de Alicante. Magíster en Investigación Educativa, Universidad de Alicante. (iD) 0000-0002-8139-7438. H5: 1. Correo electrónico: nlondono@cinde.org.co

[b] Magíster en Educación y Desarrollo Humano, Universidad de Manizales-Cinde. (iD) 0000-0001-8119-6938. H5: 5. Correo electrónico: chernandez@cinde.org.co

[c] Licenciado en Filosofía y Sociólogo, UNAD. Magíster en Educación, Universidad de Manizales. Doctorando en Filosofía y Letras Universidad de Alicante. iD 0000-0002-5252-8654. H5: 1. Correo electrónico:

tobybetan5@gmail.com 


\section{Introducción}

E ${ }_{\text {ción Los derechos humanos a través del cine, a partir de un ejercicio de investiga- }}$ ción documental -que englobó un corpus documental de 50 películas latinoamericanas acerca de los derechos humanos-, logramos develar el papel testimonial que tiene el cine para poner en los acontecimientos los diferentes rostros de la historia a través de la modelación de sus hechos. Este objetivo y las apuestas centrales de la investigación estuvieron centradas tanto en las víctimas como en los victimarios y hasta en las razones políticas y sociales que hay detrás de aquello que narra la historia. En su desarrollo, la investigación en mención logró, además de responder la pregunta por el papel testimonial del cine, visibilizar en el cine latinoamericano una serie de relatos biográficos y cruzados que proliferan, para dibujar con imágenes y sonidos realidades pasadas y que se repiten al cabo de los lustros y las décadas que van llegando. Asuntos como la minería, las relaciones de poder, la corrupción en la política, la guerra y el conflicto armado y otros filmes más costumbristas, caracterizan tales relatos, como el que permite la película La noche de los lápices (1986), objeto central de reflexión central en este manuscrito.

Sin proponer referencia cinematográfica alguna, podemos decir que las relaciones de poder dibujadas por el cine latinoamericano permiten realizar una amplia lectura de las característica de los Estados y las democracias, en la que se pueden identificar aquellos rasgos que en la realidad conocemos como un origen profundo a muchas de las problemáticas sociales que aquejan a los pueblos de esta región. Por otro lado, encontramos los paraestados, en los que el mismo poder legítima un gobierno tras bambalinas y vestido para un sainete de dificultades y pobreza. Así mismo, encontramos también aquellas películas que lograban narrar otros ejercicios de poder alternativos en los que claramente se dibujan los movimientos sociales, entre los cuales hallamos a las juventudes y los movimientos estudiantiles. 
El interés puesto en esta última categoría, lo hacemos visible bajo el análisis que puede surgir al revisar las raíces del poder y del sometimiento en tiempos de dictaduras típicas y democracias extrañas en Latinoamérica. En los desarrollos conceptuales acerca del poder y el sometimiento también emergen las prácticas de resistencia y contrapoder como acto de liberación que posibilita el cine. Esto último nos lleva a pensar que, sin proponérselo, desde su mirada el séptimo arte acoge a través de su lente una posibilidad de mirarnos y comprender el pasado de cada pueblo en todas sus dimensiones: su historia vista desde lo que ocurrió, cómo ocurrió y por qué ocurrió. Rompiendo, de esta forma, un paradigma en la manera de contar esos acontecimientos que marcan hitos en las sociedades; una manera de crear una ruptura en todas las lógicas del poder — como las que pretendemos estudiar en este manuscrito-. A través del concepto que traza el poder, marcamos de entrada un punto de inflexión sobre sus mismas lógicas en algunos territorios y, a la vez, un punto de partida alrededor de aquello que convoca este ejercicio de escritura.

Si bien no pretendemos presentar de lleno una lectura histórica y unívoca sobre los acontecimiento que giran alrededor del poder y la resistencia en América Latina, sí nos ocuparemos de revisar en lo que enmarcan las juventudes en medio de las resistencias al poder; aquellas narrativas que, con imágenes, el cine presenta, no solo para rememorar y contar un acontecimiento, sino aquellos ejercicios de resistencia a la luz del papel que han jugado las juventudes en la defensa y conquista de sus territorios en contextos de situaciones políticas difíciles en América Latina (como lo son las dictaduras y las democracias de derecha y ultraderecha). La historia suele contar estos hechos como acontecimientos cercanos, pero el cine los muestra como relatos aún por descubrir. Por tal razón, revisar este contexto histórico resulta necesario para legitimar los hitos y proponer otra forma de comprenderlos junto con la realidad de la época.

Para conjurar ese ritual cine-poder-resistencia, proponemos como epicentro y punto de encuentro la película La noche de los lápices (Olivera, 1986), la cual, en su apuesta narrativa, presenta todo un relato basado en una serie de hechos ocurridos en Argentina en los años setenta. El filme permite contextualizar la dictadura cívico militar de Rafael Videla quien, en palabras de Reato (2018), «sabía mucho más (...) sobre el destino de los desaparecidos» (§. 6). Esto no es más que la realidad que circundó el destino político de la Argentina de la época. Se decía que a la subversión — como eran llamados los opositores al régimen- no se les podía fusilar y mucho menos llevarlos a la justicia; para ellos solo quedaba un camino. El filme pone con una evidencia testimonial ese camino de aquellos opositores y, en nuestro caso de interés, de los jóvenes: la tortura y la desaparición. 
La noche de los lápices es una clara referencia para hablar de un contexto histórico puntual, pero la exposición dramática y sistemática que realiza acerca de los movimientos estudiantiles permite la consolidación de una propuesta reflexiva y analítica, que también faculta atisbar tales movimientos estudiantiles más allá de la Argentina: en Latinoamérica y otras latitudes. De esta manera lo exponen Mestman et al. (2016), destacando las rupturas políticas de ese contexto histórico para el cono sur y el papel del cine al visibilizarlo. Recordemos que, desde finales de los años sesenta, como en otros periodos de la historia las juventudes organizadas, hicieron eco de manera escalonada en diferentes lugares del globo y que, sin lugar a dudas, se ha construido un hito que marca un origen epistemológico e histórico de contexto en ese último segmento del siglo XX y lo corrido del XXI: Mayo del 68, o el Mayo francés. Para poder esbozar claramente estas cuestiones entre el contexto y los asuntos del poder, presentaremos dos acápites con el fin de tejer de una manera más sistemática y comprensible lo mencionado.

En concordancia con los acontecimientos ocurridos, y sin pretender un bosquejo del contexto social y político de la época, sino más bien buscando deconstruir los movimientos estudiantiles en el periodo histórico de las dictaduras en América Latina y otras latitudes del globo, ponemos atención para entenderlos en la relación existente entre un hito en la historia como lo es el Mayo francés y su influencia en muchos movimientos estudiantiles y de jóvenes más allá de las fronteras europeas. Por ello en una primera sección denominada «Resistencia: desde mayo hasta Latinoamérica», buscamos esa posible relación entre todas aquellas transformaciones ideológicas que pudieron influir en muchos de los movimientos sociales latinoamericanos protagonizados por estudiantes y jóvenes y que finalmente el cine dibuja su puesta en escena en películas, como lo es La noche de los lápices.

Realizando un salto desde lo referencial y los acontecimientos hacia lo conceptual, ubicamos un segundo acápite con el fin de poner de cara tanto al lector como a la estructura misma de este manuscrito el desarrollo de un concepto como el poder; este enmarca el epicentro de la película y presenta una debacle dramática para su desarrollo. Este segundo apartado permite un diálogo epistemológico entre la corriente de sistemas que enmarca Niklas Luhmann y los postulados marxistas de Nicos Poulantzas frente a la inexistencia del concepto de poder, estando este arraigado en la lucha de clases y las interacciones sociales. Estos albores teóricos posibilitarán entender el poder del Estado en sus atributos coercitivos y coactivos y su muerte frente al ejercicio de resistencia y contrapoder de 
un grupo de estudiantes que el filme logra narrar para el ojo del observador como un capítulo de la historia que se repite en la actualidad.

Finalmente, desplegamos una serie de conclusiones con el fin de cerrar el texto, sin dejar de un lado la apertura de algunos planteamientos para continuar con otros ejercicios similares que, desde el cine, permiten la lectura de contextos similares.

\section{Desarrollo/análisis}

\section{Resistencia: desde mayo hasta Latinoamérica}

Sin querer, planteamos en este acápite el inicio de nuestro recorrido, tanto por la historia como por la película y los asuntos del poder que esta nos permite visualizar. Por ello, frente al plano de lo histórico, es menester plantear que a ese asunto nos tomamos el atrevimiento de nombrar como génesis de muchos de los movimientos estudiantiles en América Latina: las revueltas estudiantiles ocurridas en Francia entre mayo y junio de 1968, sin desconocer que previamente durante las primeras décadas del siglo XX grupos universitarios salían a las calles a pregonar ideales de libertad y socialismo, ligados a los acontecimientos de transformación de la clase campesina en clase obrera (GonzálezArana, \& Molinares-Guerrero, 2012). Así mismo, que luego en 1966, en el cuarto Congreso Latinoamericano de Jóvenes, se propendería por «promover la solidaridad activa de los estudiantes del continente en la lucha contra el imperialismo y a consolidar los vínculos que los unían con los campesinos y con los obreros» (Meyer, 2008, p. 180). Años después otros hitos sumarían a construir un historial de la influencia política de los estudiantes en las esferas estatales.

Retornado al capítulo del Mayo francés, hallamos que entre los menos escépticos de la academia se dice que los movimientos revolucionarios franceses de 1968 no lograron cuajar, ni fueron duraderos; pero otros sí encuentran una raíz a cambios estructurales que en la actualidad reflejan esperanza, como lo es el caso de Estefanía (2018), quien en su libro Revoluciones: cincuenta años de rebeldía, pone en evidencia la cantidad de causas que acunó el Mayo francés. En un paneo general traemos a colación lo siguiente: el ecologismo, la libertad sexual, la educación igualitaria y el feminismo. Los estudiantes franceses en el 68 fueron testigos de una transformación de ideas y valores morales. Las revueltas en aquel mayo no cambiaron el poder, ni el sistema, pero sí actuaron como el fuego que permitiría la eclosión de libertades y causas. Los derechos civiles, el antinuclearismo, la 
revolución sexual y el antibelicismo tuvieron cobijo bajo un paraguas que reclamaba una nueva moral y una nueva sexualidad. Los estudiantes torturados y desaparecidos en la «noche de los lápices» quizás no derrocaron la dictadura de Videla, pero sí quedó en la memoria de los argentinos y los latinoamericanos un proceder sistemático para la desaparición y el acallamiento de las voces de quienes pensaban diferente y querían respuestas distintas por parte del Estado.

Los franceses pudieron ver el momento exacto en el que las perspectivas libertarias se canalizaban hacia el feminismo, la ecología y la lucha contra el racismo. Seguramente recordarán que todos son hijos de aquel Mayo francés, como lo expresarían Glucksman y Glucksman (2018), en homenaje a los 50 años de este hito; estos se fijan notablemente en el papel de los y las jóvenes en la actualidad. Además de esto, es notable también para los últimos años una nueva tradición de derechos que vinieron con el ecologismo; unos derechos de tercera generación que, décadas más tarde, se verían reflejados en una nueva generación de constituciones políticas (Estefanía, 2018), como sucedió en Colombia, donde también el movimiento estudiantil tuvo una injerencia directa con la denominada «séptima papeleta». Pero años atrás en América Latina fuimos testigos de la caída del régimen en Ecuador y Bolivia y el apoyo a los movimientos frente a la crisis mexicana y la firma del pacto multicultural entre Brasil y Estados Unidos. Una clara evidencia de una multicausalidad de hechos históricos al rededor del mundo.

El contexto de la guerra fría ponía de cara al mundo a una América Latina plagada de dictaduras y democracias restringidas a un solo poder o, recurriendo a un eufemismo, «dictaduras democráticas». Ese contexto histórico nos lleva a la necesidad de realizar varios saltos espaciales, en los que pondremos la mirada de manera alternada entre la película y las diversas realidades que nos entrega el contexto de la época. Se conjura así esa relación cine-poder-resistencia que, en medio de una realidad histórica como la de la guerra fría, entrega para la actualidad una génesis importante para muchos de los problemas sociales y políticos de la época de las dictaduras típicas en América Latina (Mestman et al., 2016) y que hoy aún lamentamos sin saber la suerte de sus víctimas desaparecidas. Hacemos mención de las dictaduras toda vez que, durante la Guerra Fría, fueron un común denominador entre las formas de gobierno de algunos países. A esto, Arratia (2010) hace una mención importante en la que, además de hacer uso de un término ya acuñado, propone una característica que, en este ejercicio analítico, termina operando como característica de análisis: «En tiempos de la Guerra Fría la característica de Latinoamérica era la dictadura militar» (p. 35); por ello que este autor - y otros antes- hablan de dictadura 
típica a manera de hito. Nombres como Jorge Rafael Videla y Augusto Pinochet nos pueden resultar familiares, pero antes y después de ellos llegarían otros más, quienes otorgarían desde una lectura histórica una característica típica al continente latinoamericano desde el centro hasta la Patagonia: la dictadura.

En esta época de Guerra Fría el mundo era objeto de cambio. La cultura juvenil lo reflejaba desde sus muestras de rebeldía, que crecía al mismo ritmo que la sociedad de consumo estadounidense; se abría paso y configuraba una cultura del ocio insólita hasta ese momento. 1968 fue un año de eventos multicausales hacia un mismo objetivo: en América Latina los jóvenes conformaban redes antiimperialistas; en Francia se desataban otras expresiones de lucha y resistencia que se expandirían por todo Europa; en Estados Unidos Martin Luther King era asesinado; las protestas juveniles en contra de la guerra de Vietnam no cesaban en todo el globo; las protestas en México y Checoslovaquia contra el comunismo; el asesinato del joven activista Rudi Dustchke en Alemania. Todo ello era más que preavisos que el mundo tenía nuevos protagonistas en las esferas políticas; que sin tomar decisiones en medio de los anaqueles gubernamentales tenían influencia en ellas.

Las menciones realizadas nos dan cuenta que el protagonismo estudiantil y juvenil no era solo un asunto francés; pero nos fijamos en ello por esa imprenta cultural y popular en un muro que dicta una sentencia de revolución y cambio. Como proclama de lucha, lo imposible permitiría a muchos estudiantes en el mundo soñar y poner sus apuestas de libertad y resistencia en marcha. La icónica frase «seamos realistas, pidamos lo imposible» (Facultad de letras, Universidad de París), dejó de ser solo una inscripción para convertirse en un simbólico grafiti con el que el movimiento del Mayo francés; más precisamente, los jóvenes estudiantes pintaban las calles de París, la cual, además, vivía entre barricadas. La euforia de estos jóvenes (que arremetían para conseguir lo imposible y que, sin importar las circunstancias, tenían prisa por lograrlo) se sumaba a oleadas de otros movimientos alrededor del mundo, dejando a ese mayo de 1968 marcado en la historia como un año de resistencia y contrapoder.

La capital francesa se convirtió hace más de medio siglo en el epicentro de una protesta estudiantil sin precedentes, sumada a una huelga general de múltiples personas. Desde entonces estos acontecimientos son una huella llamativa - a veces borrosa y, sin duda, polémica- en la memoria, no solo de los franceses, sino de gran parte de las sociedades actuales. A la par, otra huella —esta vez imborrable - se iba construyendo en Latinoamérica, también con una serie de movimientos estudiantiles sin precedentes. Muchos de estos estudiantes nunca podrían dar cuenta de su ejercicio de resistencia a la dominación y 
la coacción por parte del Estado. Por citar un ejemplo, traemos a este texto la «noche de los lápices», no como película, sino como acontecimiento. Estos sucesos han venido siendo el reflejo y fuente de inspiración para fenómenos similares en diversos y variados lugares del mundo en la actualidad. Por ello, se puede afirmar que el peso simbólico de estos acontecimientos sobrepasa las fronteras de la historia y de los lugares. Como lo afirma uno de sus instigadores — conocido en la época como Dany el Rojo-:

1968 fue una revuelta planetaria. Si uno se pone a pensar en los finales de los años 1960, se discierne una revuelta tanto en el Este como en el Oeste, tanto en el Sur como en el Norte. Casi en todas partes se dan revueltas, ocupaciones de universidades o colegios, manifestaciones. La prueba es que, si hoy escriben un libro, basta con poner en la carátula dos cifras: 6 y 8 -68-y, automáticamente, la gente (en Turquía, en América Latina, en Praga o en Varsovia, en París o en Berlín, en Nueva York o en San Francisco, en Sarajevo o en Río), (...) de una vez piensa en el año 1968, en la revuelta de finales de los años 1960. (Cohn-Bendit, 2008, p. 5)

Para los jóvenes del momento y para los de las sociedades actuales, el Mayo francés se convirtió en una forma de resistencia que dejó imborrables huellas para la configuración de sus porvenires. En ese sentido, en Latinoamérica no se «conciben a los individuos jóvenes como aquellos agentes que problematizan las realidades sociales, políticas y económicas, es decir, que potencian la sociedad con sus ideas de transformación» (Parra-Valencia et al., 2018, p. 855). Por tanto, la importancia de dimensionar la influencia de los jóvenes en la región se evidencia al analizar que este periodo de la historia se ha instaurado en las dinámicas y los discursos que permiten la configuración de muchas variantes contrapuestas los poderes jerárquicos y organizados. La resistencia y el contrapoder, como lo mencionaría Bourdieu (1996), como un ejercicio de ir en contra de la hegemonía. Por ello, no es extraño ni casual que el movimiento estudiantil del Mayo francés tuviera entre una de sus banderas al libro Los herederos de Pierre Bourdieu. Sin embargo, y reconociendo su magnificencia, no debemos encapsular todo un movimiento expandido a nivel mundial en un solo lugar del mundo; así lo da a entender el mismo Cohn-Bendit (2008):

No se puede reflexionar sobre el significado de esta revuelta reduciéndola a un solo país, aunque sí fue en Francia en donde la revuelta fue más intensa, ya que, contrario a lo que pasó en los otros países, desembocó en una huelga general. En ese sentido, existe entonces una especificidad francesa del 68, pero ésta se inserta en el marco de un movimiento más general. (p. 5) 
Estos movimientos se han convertido para los jóvenes en una búsqueda de reivindicación política al reclamar sus derechos y reconocimiento, en especial desde la educación superior y en esferas donde la agitación social está al orden del día. A partir de allí es importante señalar que «la participación de los jóvenes y las jóvenes en este escenario permite comprender su actitud frente al sistema político» (Peralta-Duque, 2016, p. 1263). De la misma forma, estos eventos han permitido las luchas por la reivindicación de derechos en la región. Además, otros eventos como la «Primavera de Praga» en Checoslovaquia, las manifestaciones contra la guerra de Vietnam y principios de la contracultura hippie en Estados Unidos y algunos países europeos como Alemania y Holanda (CohnBendit, 2008; Rotman, 2008) resurgieron en ese mismo transcurrir temporal en oposición nuevamente a esos poderes hegemónicos que se vislumbraban. A esto es importante añadir lo que, tanto para Gramsci (2008) como para Bourdieu (1996), es el análisis del sentido común que se vincula a estos hechos, para comprender los mecanismos de dominación simbólica (en este caso de las oposiciones que declaraban los jóvenes en estos acontecimientos). Estos instalaron un poder contrahegemónico en términos gramscianos y herético en términos bourdeanos; términos que llenaron de coraje a los jóvenes protagonistas de las manifestaciones presentes en la «noche de los lápices».

Para una primera referencia a esta película, los jóvenes de La noche de los lápices se reunían para tomar una decisión muy importante: salir a protestar hasta el edificio de obras públicas o solo dialogar con el gobierno. La dictadura había decidido dejar de entregar el boleto estudiantil secundario, una compensación económica que reducía los gastos en transporte, aliviando la economía de los estudiantes. Para una caracterización momentánea de estos jóvenes, diremos que eran los encargados de impartir algunos asuntos ideológicos a niños de diferentes barrios de La Plata, buscando que estos fueran capaces de exigir sus derechos.

Al igual que en Francia, la trama de la película refleja la apuesta de un escenario en el que se exacerbaban los niveles de descontento juvenil y la inadaptación de las estructuras universitarias frente a la llegada masiva de estudiantes. En aquella época había una serie de problemas de infraestructura y métodos de enseñanza, obligando a formatos de clases magistrales en auditorios superpoblados (Le Goff, 2006; Rotman, 2008). Por su parte, el sector obrero no es ajeno a estas situaciones y enfrenta una serie de cambios; según Laurent (2009), los más destacados de dichos cambios son los siguientes:

Mientras se difunde la creencia en el progreso, se impone el modelo de la sociedad de consumo y se generaliza el acceso a productos electrodomésticos, incluso entre las capas 
más populares de la población; por otro lado, crecen las necesidades del sector empresarial de un personal cada vez más calificado y técnico. Paralelamente, empiezan a hacerse visibles, en las grandes urbanizaciones, signos relevadores de chocantes desigualdades sociales: aparición y expansión de barrios de invasión, construcciones masivas de viviendas subsidiadas. (p. 31)

Estas transformaciones, en su mayoría de orden económico, marcan el reflejo de la sociedad europea y los centros en las sociedades latinoamericanas, en parte agenciadas desde los Estados. Esto lo podemos referenciar como un «llamativo contraste entre la modernización económica que implica y el conservatismo extremo que se mantiene en el campo de las relaciones sociales» (Laurent, 2009, p. 31). Estas últimas están caracterizadas por ser extremadamente cerradas y verticales, siendo enmarcadas por una serie de instituciones: Estado, empresa, sindicato, Iglesia y escuela (Rotman, 2008); lo que sería sin duda un detonador de las revueltas que, recordando nuevamente, pedían lo imposible. Situaciones mismas que se encendían con mayor fuerza en los contextos latinoamericanos debido a esa dualidad de centro-periferia y que hoy mismo siguen siendo un común denominador en la sociedad.

Pedir lo imposible, en el ideal de esa resistencia y contradicción que enmarcan al ser joven, alude a varios asuntos dialécticos, como lo es hablar de lo opuesto o, como se mencionó, de lo contradictorio. Contradictorio, primero porque se resiste a la lógica binaria de que lo posible es lo realista, es decir, pedir lo imposible es no ser realista; y, segundo, porque esa consigna estaría plagando a los jóvenes de unas múltiples categorías como idealistas, utópicos, soñadores, revolucionarios..., a las que finalmente terminan huyendo como una resistencia, no solo de los poderes hegemónicos, sino de otras esferas de la sociedad como los adinerados o hasta sus mismos padres, quienes ostentan posturas conservadoras.

«Seamos realistas, pidamos lo imposible». El juego de esta frase con la que direccionamos de una u otra manera el epicentro de esta sección permite caracterizar los movimientos estudiantiles y juveniles de una época trastocada en el tiempo; son los jóvenes de hoy, pero fueron también los de ayer y seguro serán los de mañana. Así lo narra la película en medio del cambio invocado por los jóvenes durante la dictadura de Jorge Rafael Videla. Para estos jóvenes de La noche de los lápices salir a protestar y llevar los derechos humanos a las calles era una directa manera de invocar el cambio. En medio de sus reuniones se pensaba el hecho de ser realista y aceptar solo lo posible y perder la convicción sobre transformación de las cosas; o salir a las calles sin imaginar que muchos de ellos 
no podrían siquiera volver a hablar de convivencia pacífica de derechos humanos o del bono escolar para el transporte.

Precisamente, esa juventud de La noche de los lápices, al igual que aquella que protagonizó el Mayo francés, instauró unas nuevas y polémicas acerca de ese estado de quietud o de aceptación de ciertas realidades. Cada punto que abordamos con el lente de una juventud revolucionaria que se disputaba con todos los niveles del poder existentes, enmarca una visión de no aceptación de ese estado de quietud y no convicción por modificar una realidad; desaparecidos sus cuerpos y silenciadas sus voces, continúa el reflejo de no parar y hacer frente a esas realidades instauradas en las estructuras y las relaciones de poder entre grupos y clases. Los jóvenes argentinos de la película, los de la realidad y los del Mayo francés conocían muy bien esas estructuras y su capacidad represiva: «Estructuras que son capaces de condicionar y orientar las prácticas y representaciones de los agentes por medio de esquemas de percepción subjetivos a través de los cuales los agentes se representan el mundo social e interactúan dentro de este» (Di Napoli, 2013, p. 6). A esto, Bourdieu (2000) señala que, bajo estos supuestos de instauración del poder, es necesario realizar una doble objetivación que supone dos momentos de ruptura con el objeto de estudio (la realidad histórica y cinematográfica que estudiamos):

Por un lado, las estructuras objetivas que construye el sociólogo en el momento objetivista, al apartar las representaciones subjetivas de los agentes, son el fundamento de las representaciones subjetivas y constituyen las coacciones estructurales que pesan sobre las interacciones; pero, por otro lado, esas representaciones también deben ser consideradas si se quiere dar cuenta especialmente de las luchas cotidianas, individuales o colectivas, que tienden a transformar o a conservar esas estructuras. (p. 129)

Sin embargo, el análisis sobre el proceso de instauración de estos modos de subjetivación de la realidad dista del objetivo que pretendemos; por ello, tan solo lo situamos como un apoyo a lo mencionado en relación a un estadio de aceptación de lo que es posible o no instaurado desde las esferas del poder. Este poder, divagando entre todo esto, tiende a convertirse en un mero hecho de gestión, de administración...; casi que distante de esa posibilidad por alcanzar ese algo. Y es sumamente importante analizar el concepto de posibilidad porque, por ejemplo, Pöggeler (1993) decía que el hombre es básicamente un proyecto abierto; posibilidades y decisiones que, tomadas por los jóvenes en su época de furor -cine o realidad-, permiten develar un testimonio aún vigente: todo poder tiene su contrapoder. 
Entonces, ¿por qué después de los acontecimientos que narra la historia y aquellos que narra el cine en su discontinuidad temporal asociamos esa idea de lo posible a lo que existe y no puede modificarse? Esto es, lo posible como aquello que se conserva y que viene a pelearse con aquellas ideas que, por utópicas, son imposibles; por ejemplo, acabar con la dictadura o la hegemonía burguesa de la modernidad. De ahí que, para Poulantzas (1982) el concepto de hegemomía «se inserta en toda una problemática particular del materialismo dialéctico concerniente a la vez al problema de las relaciones entre base y superestructura y al de la especificidad del dominio político y estatal en una formación social históricamente determinada» (p. 1).

A partir de lo antes mencionado, se evidencia el control que ejerce la hegemonía sobre los cimientos de la formación social, la cual está determinada e influenciada por los discursos de poder. En ese sentido, se dicotomiza la idea de lo político en dos extremos: en un lado, ese optimismo exacerbado que caracterizó el movimiento de aquellos jóvenes desaparecidos que nos muestra la película; aquellos jóvenes muertos a lo largo de toda América Latina y otros que pelearon en el Mayo francés, quienes entendían que la verdadera realidad se halla en una que se transforma todo el tiempo; de ahí que ser realista sea pedir lo imposible. Y, del otro extremo, recordando unas de las más conocidas definiciones de Aristóteles (ca. 384 a. e. c.) sobre la política: el arte de lo posible. En ese punto hallamos el análisis a unas posibles razones por las cuales la resistencia de los jóvenes a esos modelos tradicionales de concebir, no solo la realidad, sino la posibilidad, han emanado en forma de contrapoder a esas hegemónicas que modelan la realidad y direccionar el pensamiento.

Ahora bien, dentro de esa mirada analítica frente al significado para los jóvenes en muchas latitudes, la resistencia de un acontecimiento como el Mayo francés a esos poderes que se habían consolidado permite recabar en la categoría de la imposibilidad. Esa imposibilidad dentro de lo señalado por Derrida (2001), quien menciona que se vuelve posibilidad hacer lo imposible y lograr dar un paso más. El propio Heidegger (2005) termina ligando estas expresiones al concepto de libertad en su texto ¿Qué es metafísica?, pensando que, habérselas con la no-posibilidad o la imposibilidad, es exactamente habérselas con la muerte. ¿Qué habría pasado con los estudiantes del Mayo francés si se quedan taciturnos y silenciados por la imposibilidad?, o ¿qué habría pasado con los estudiantes de La noche de los lápices si se hubieran quedado callados?, ¿estarían vivos aún?, quizás estarían contando una historia que nunca existió.

Este contexto desarrollado hasta el momento, ser realista es luchar por lo imposible, y esa lucha se vuelve efectiva, es decir, se consigue aquello por lo que se pelea; nace una 
posibilidad más. Este orden de ideas, permite la emergencia de una pregunta planteada en plenaria por los jóvenes de La noche de los lápices: ¿renunciamos definitivamente a lo imposible? Este interrogante se convierte en una manera también de situar los poderes, no solo de la época, sino los que han surgido en las sociedades actuales en una idea de democracia no definitiva; es decir, implica una continua lucha por seguir democratizando un país y un continente azotado por dictaduras militares y cívico-militares. Así, el legado que fue consolidándose tras la «noche de los lápices» y el Mayo francés lo plasmamos alrededor de la lucha por lo imposible, como una búsqueda por instaurar nuevas sociedades, no únicamente hacia la revolución, sino en dirección de una democracia dispuesta al cambio, no estática.

Por otro lado, el universo de los jóvenes y sobre todo el movimiento estudiantil que se manifiesta hasta hoy en los campus universitarios, en las calles y las comunas en Latinoamérica sirve como detonante a ese deseo - muchas veces compartido- de conseguir lo imposible y transformarlo en una posibilidad. A su vez, cada uno de los postulados que inflan los ánimos y el descontento social se quieren desvincular de los poderes que, hegemónicamente organizados, representan casi siempre una minoría por encima de unas masas o mayorías desorganizadas. Ello lo estudiaría a profundidad Gramsci (1974, como es citado en Noguera-Fernández, 2011) en la dimensión simbólica o superestructural de las relaciones sociales. Como van en contra de esos regímenes, son una forma de contrapoder, no solo en los aspectos que refieren al poder político, sino también al económico, psicológico, sexual y hasta intelectual. Estas ideas en gestación ocupan la mente de los jóvenes e intensifican los cuestionamientos que dan un sentido a un malestar real y profundo.

Aquella reunión de estudiantes en La noche de los lápices hizo una apología a ese grafiti pintado en mayo del 68, significando la construcción de un instrumento de lo imposible convertido en posibilidad (Heidegger, 2005): irse contra la dictadura de Videla. Es también una muestra sobre el fondo de una revuelta que se piensa, no para el caos o el desorden (como las miradas más conservadoras de algunas clases sociales así lo conciben), sino que se apoya en una lectura del mundo, profunda y original, tan vigorosa como la misma protesta. Es verdad que otras interpretaciones lo puedan vislumbrar; una fuerte tendencia hacia la poética del discurso político. Pero más allá de eso, es una muestra de la espontaneidad de aquellos estudiantes que, en distintos contextos del mundo, navegaban entre esos poderes instaurados por las ya mencionadas hegemonías y dictaduras; y su férrea forma de contrapoder significó la toma del destino en manos propias para nutrir los ansiados cambios por medio de los espíritus de unos jóvenes coléricos. 


\section{Del poder al contrapoder y la resistencia}

Iniciaremos esta segunda parte de la reflexión resaltando aquellos elementos de la película que encajan directamente con ese análisis de las dinámicas de poder ya perfiladas en la última parte del acápite anterior. Mencionado desde el principio, La noche de los lápices aborda su trama a partir de un acontecimiento real ocurrido en Argentina en 1976 y que 10 años después —en la pared blanca del cine - se conmemora con imágenes desgarradoras, poniendo para el espectador una posibilidad única de dejarse absorber por ese pedazo de la historia y participar de manera directa de la escritura de esa otra frase inolvidable «los lápices nunca dejaron de escribir»; a partir de la suerte de tan solo siete jóvenes propone una lectura quiromántica sobre el destino de miles de jóvenes en América Latina y el mundo. La película permite, más allá del drama, acceder a los personajes y sus sentimientos en lugar de una simple lectura testimonial de un evento ya ocurrido. Los estudiantes en sus encuentros hablan sobre protestas y otras formas de activismo, como la pedagogía popular y la educación en derechos. Una búsqueda por reivindicar aquello que se iba a perder con la nueva junta de gobierno instaurada por Jorge Rafael Videla y que significaría una sujeción hacia la dominación y violencia estructural del Estado. Lo que encontraron fue terrible; la violencia armada amenazaba con silenciar sus protestas y silenciar sistemáticamente su ejercicio de ser jóvenes.

Tal y como lo enuncia Saldarriaga (2011), el cine presenta conceptos en su dimensión imagen-tiempo, más no los devela. Resulta paradójico, pero está en el espectador la responsabilidad de hallar el concepto y traerlo a la realidad. Por ello, y para nuestro caso, en la película La noche de los lápices la fecha de los acontecimientos es hoy un aniversario diario de alcance internacional. Por su parte, Raggio (2011) nos relata cómo en el 76 en la ciudad de La Plata un grupo de estudiantes fue secuestrado por las Fuerzas Armadas. La autora entra en detalles como los nombres de aquellos jóvenes: Francisco López Muntaner, María Claudia Falcone, Claudio de Acha, Horacio Ángel Ungaro, Daniel Alberto Racero, María Clara Ciocchini, Pablo Díaz, Patricia Miranda, Gustavo Calotti y Emilce Moler. Además de una conexión documental muy fuerte en el relato de esta historia, la película logra sintetizar algunos de los elementos más profundos de las memorias sobre el terrorismo de Estado en esa época contra la sociedad civil, centrando sus ataques contra los albores libertarios de los jóvenes. «La novedad que aporta este poderoso artefacto cultural es la representación del mundo concentracionario. Ha sido la primera película que cuenta una historia desarrollada en un centro clandestino de detención creando los 
primeros fotogramas del horror» (Raggio, 2011, p. 3). Una vez más el cine logra trascender las fronteras espaciales: aquello ocurrido se puede sentir como un hecho vinculado a la realidad de muchos países.

Los relatos cinematográficos que encontramos en La noche de los lápices constituyen un hito de la memoria social. Raggio (2011) es contundente al reconocer el valor que tiene este texto cinematográfico para reflexionar acerca de la construcción de esa memoria (y sus transformaciones en función de los cambios del presente), de la biografía de los protagonistas y de los hechos vinculantes con la historia. Son estudiantes jóvenes con un ejercicio de lucha fácilmente comprensible y carente de ser objeto de impugnaciones y controversias para la actualidad. Sin embargo, «se trata de un poder desmaterializado, invasivo, libre de resistencias físicas y territoriales, expandiendo sus tentáculos hacia mucho más allá que la televisión, que la radio, que los medios impresos y que el cine» (De Moraes et al., 2014). En ese sentido, el peso de la hegemonía cobra fuerza al introducir formas de pensamiento manipulado y control social; de ahí que el drama de los jóvenes de la película en su primera reunión, en su paso por los centros clandestinos de tortura y demás hilos permite hallar en la película un binomio conceptual que podríamos decantar entre el poder y la resistencia o el contrapoder.

Para entender esta emergencia conceptual entre los ejercicios de poder y contrapoder en el filme es necesario atisbar, de un lado, la corriente de la teoría de sistemas en la que se fundamenta Niklas Luhmann y, del otro, los asuntos sociológicos y marxistas en los que Nicos Poulantzas plantea sus argumentos alrededor del poder y el contrapoder; ambas posturas son importantes para analizar esos dos lugares de enunciación: Estado y estudiantes. Sobre el poder, Luhmann (2015) señala la posibilidad de entenderlo como un instrumento de la comunicación, en la medida en que este solo es posible a través de las interacciones entre los sujetos y los sistemas. Aunado a esto, Castells (2013) y Korstanje (2010) mencionan, acerca de las capacidades relacionales del poder, que son los códigos que permiten su comprensión intersubjetiva; «un código cuya función es hacer inteligible las opciones entre alter y ego. En la vida diaria existen códigos generalizados que permiten la comprensión intersubjetiva por medio del lenguaje. La comunicación intentará, por todos los medios, resolver la contingencia» (Korstanje, 2010, p. 132). A esto, Luhmann (2005) señala:

El poder funciona como un medio de comunicación. Ordena las situaciones sociales con una selectividad doble. Por lo tanto, la selectividad del alter debe diferenciarse de la del ego, porque en la relación de estos dos factores surgen problemas muy diferentes, espe- 
cialmente en el caso del poder. De acuerdo con esto, una suposición fundamental de todo poder es que la inseguridad existe en relación con la selección del alter que tiene poder. Por las razones que sean, alter tiene a disposición más de una alternativa. Puede producir y quitar inseguridad en su compañero cuando ejerce su elección. (p. 13)

Esa codificación alter-ego es notable en la película; su representación en esos dos lugares de enunciación ya mencionados (Estado y estudiantes) permite hacer hincapié sobre las características de las relaciones comunicacionales del poder. Según Luhmann (2005) los códigos que dirigen una interacción (como ocurre en la película) lo están en su rol de promotores de las relaciones sociales de algunos atributos notables y comprensibles del poder. Sobre ello Korstanje (2010) afirma: «La posibilidad del subordinado de elegir cómo comportarse se encuentra vinculada a la expectativa de que alter ejerza alguna acción. Existe, en consecuencia, una dicotomía (un binomio) entre las acciones posibles que una persona puede seguir» (p. 132). Las protestas protagonizadas por los estudiantes representados en el código alter estuvieron mediadas entre dos posibilidades: protestar o dialogar con el gobierno - ego-; este último actuó en la medida de las mismas posibilidades otorgadas por esa capacidad comunicacional del poder: la represión. Luhmann (2005) permite entender esta dimensión de la siguiente manera:

La atribución del poder al poderoso está regulada en este código por los resultados de amplio alcance que conciernen al refuerzo de motivaciones que cumplir, responsabilidad, institucionalización, dando una dirección específica a los deseos de cambio. Aunque están actuando ambas partes, cualquier cosa que ocurra se le atribuye solamente al poseedor del poder. (p. 23)

En efecto, el portador del poder queda escindido en la realidad como el único responsable de las situaciones que se van suscitando. Así lo ponen en evidencia Grimmson y Bidaseca (2013) al proponer un ejercicio de políticas de diferencia alrededor de la hegemonía; ello es respaldado por Castells (2008), quien resalta entre resultados y posibilidades los efectos relacionales del poder entre la sujeción y el sujeto respecto a los nuevos espacios para la comunicación. Uno de los ejemplos que podríamos exponer, y que es señalado por la corporación argentina Educación y Memoria (2001), es el desgaste político que se observó por parte del gobierno buscando malversar los ejercicios de resistencia de los jóvenes estudiantes:

La mayoría de los jóvenes tenían militancia política. Muchos habían participado, durante la primavera de 1975, en las movilizaciones que reclamaban el BES (Boleto Estudiantil Se- 
cundario), un beneficio conseguido durante aquel gobierno democrático y que el gobierno militar de la provincia fue quitando de a poco - subiendo paulatinamente el precio del boleto- a partir del golpe del 24 de marzo de 1976. Por otro lado, buena parte de los estudiantes integraba la UES (Unión de Estudiantes Secundarios) y la Juventud Guevarista, entre otras organizaciones. (§. 6)

Respecto a lo anterior, Luhmann (2005) insiste que la función del poder es actuar como productor de posibilitadores de selección:

El poder puede hacer demandas a la voluntad, la puede obligar a absorber riesgos e inseguridades, incluso la puede llevar a la tentación y dejarla frustrada. Los símbolos generalizados del código, los deberes e insignias del cargo y las ideologías y condiciones de legitimización sirven para ayudar al proceso de articulación, pero el proceso mismo de comunicación sólo cristaliza motivos cuando se está ejerciendo el poder. (p. 31)

En las asociaciones que podríamos realizar frente al concepto del poder, entre libertad y coerción, opresión y comunicación, nos encontramos con Chul-Han (2018). En un intento por recoger muchas acepciones teóricas sobre el poder, este autor nos permite entender un poder que en un nivel conceptual y real se presenta de forma dinámica; por ello es que siempre hallamos, para un ejercicio de poder, otro de contrapoder. Ello condiciona el alcance o no de un objetivo trazado: «Los portadores de poder son frecuentemente portadores también de éxitos o fracasos aun cuando ellos no quieran serlo» (Korstanje, 2010, p. 134). Sobre el poder y la película, Luhmann (2005) nos permite entender que este constituía para dicha dictadura cívico militar su manera de comunicar: «Es el medio de comunicación propio del sistema político» (p. 6o).

Dejando de un lado las apuestas sobre el poder en la dictadura, y fijándonos más en los ejercicios de resistencia y contrapoder de los estudiantes, hallamos las consideraciones de Nicos Poulantzas acerca de esa referencia a la disputa por el poder o la conquista del Estado por parte de la sociedad civil. El concepto del poder es inexistente (Poulantzas, 1985); pensando en ideas cercanas al poder (como el concepto de Estado) como un espacio de relaciones sociales y de poder, o un campo de relaciones de fuerza en disputa, entran en juego una serie de decisiones: tomar el poder a través de elecciones, pero combinando esto con movilizaciones sociales y rompiendo con el concepto del poder dual como un ataque insurreccional al Estado. Lo que el gobierno argentino imperante temía en la «noche de los lápices», y precisamente lo que tenían los estudiantes en su elección, era una conquista. El Estado debe ser tomado desde adentro y desde afuera, desde arriba 
y desde abajo, podrían haber pensado aquellos estudiantes la noche previa a su secuestro, y es precisamente como lo define Poulantzas en su haber marxista para relacionarse con el Estado como materialización conceptual del poder.

Las precisiones de Poulantzas alrededor del poder las encontramos muy arraigadas al concepto de Estado, donde las relaciones que caracterizan a ese poder impregnan la estructura misma de su aparato. Así, el Estado es la condensación de una relación de fuerzas, pero lo hace pensando en las clases sociales y en los puntos de quiebre con relación a la resistencia y el contrapoder hacia este mismo. «Precisamente esa naturaleza del Estado - del Estado como relación-, atravesada de lado a lado por contradicciones de clase, es la que les atribuye y permite a esos aparatos y a los agentes que los componen un papel propio y un peso específico» (Poulantzas, 1975, p. 104). En este punto de la discusión el Estado como dimensión se deconstruye y se construye con los nuevos actores políticos y sus decisiones que, según la película, permiten la emergencia de un ejercicio de lucha; no entre clases, sino entre el Estado mismo y la sociedad civil, en este caso representada por los jóvenes en ejercicio de contrapoder al poder del Estado.

De otro lado, Poulantzas (1978) anota que se debe entender al Estado como un «conjunto de instituciones públicas y privadas ubicadas en la superestructura y que desempeñan esa función de organización de la clase dominante y desorganización de la clase dominada» p. 169). La diferencia entre el dominante y el dominado llega a marcar un rumbo importante en los acontecimientos del 16 de septiembre de 1976 recogidos por película, permitiendo entender esas dinámicas de poder estatal y unas dinámicas emergentes de contrapoder y resistencia. Sin embargo, pese a que el autor permite esta lectura de contexto, no enfatiza tanto en esa posición y función del aparato de Estado, mientras que Luhmann sí lo hace. La noche de los lápices permite medir esa condensación de relaciones de fuerza o, como el mismo Poulantzas (1978) diría: «la inscripción de la dominación política en la armazón material del Estado» (p. 192). El Estado tiene el aparato necesario para ejercer el poder y, además de ello, la violencia. Es por esto que el poder existe por medio del Estado y a raíz de otros aparatos o ramas que generan un determinado poder propio de las clases sociales en las cuales se configura el mismo Estado; lo anterior, a pesar de se haga bajo la compactación del poder estatal, de donde surge una especie de hegemonía en función de las clases y fracciones dominantes. «Por su parte, las clases dominadas no existen en el Estado por intermedio de aparatos que concentren un poder propio de dichas clases sino, esencialmente, bajo la forma de focos de oposición al poder de 
las clases dominantes» (Poulantzas, 1978, p. 172). Dichos focos son manifestados por los jóvenes de La noche de los lápices como contrapoder y resistencia.

La película permitió, desde la mirada de estos dos autores, hallar una referencia clara alrededor del papel de las juventudes en la conquista de sus derechos, de los territorios (en cierto modo) y del ejercicio del poder. De igual forma, identificar algunas posturas y concepciones del poder sin duda cortas y a lo mejor vacías, pero un claro reflejo de lo que sucedió y, quizás, lo que seguirá sucediendo. En este sentido, el cine permite que el espectador se mire al espejo; pero el tiempo que ese espejo refleja podría llegar a ser una bifurcación de una o más realidades. Este filme permitió la comprensión de varias particularidades de un concepto tan sublime como el poder en un momento tan crítico como lo es el siglo XXI a través de la mirada del pasado.

\section{Conclusiones}

Como punto de partida, ese revuelo del Mayo Francés, instaurado por unos jóvenes cargados de ideologías y teorías tan diversas, fue el causante de cambios en dominios numerosos y variados, además de ser un tiempo acelerador de procesos y el revelador de malestares hasta entonces escondidos. No se puede negar que fueron las acciones de pequeños grupos minoritarios y radicales las que cambiaron a la sociedad. Esa consigna de «sean realistas, pidan lo imposible» de la que se desprende este trabajo, fue el motor de una re-evolución real y profunda. «Paradójicamente, la crítica del marxismo tradicional vino de pensamientos más revolucionarios que aquellos empleados por los comunistas clásicos, y ahí se puede ver un signo de su declive» (Poulantzas, 1985, p. 34) y, por ese medio, quizás se pueda decir que la contestación podría dirigirse tanto a la sociedad capitalista como al mundo socialista y estatal; pero eso es discusión para otro momento.

Hay que señalar también que estas lecciones han sido retomadas en países con una juventud ansiosa de expresar una oposición y un malestar por mucho tiempo guardados. Por ejemplo, México, que conocería semanas más tarde una rebelión estudiantil amplia y severamente reprimida, seguramente recibió más influencia de campus universitarios estadounidenses y de la contracultura que ahí circulaba. Pero esta agitación no acabó ahí y se volvió planetaria y ha mostrado que los nuevos valores en gestación revolucionaria se cruzan, se intercambian y se multiplican de un territorio a otro. La juventud —sobre todo estudiantil_, en medio de ese poder y su contrapoder, se convirtió en una fuerza 
de oposición fundamental, la cual no dejará ese lugar conquistado. Su resultado y más que todo privilegio, fue ocupar una posición que nadie podía tomar; una posición de un camino lento, pero que convertiría lo imposible en posible. Ante esto, el cine ha sido una ventana para explorar y volver a los acontecimientos; vivirlos y poderlos comprender.

Queda entonces para las actuales juventudes - y ese aire aún conservado de revolución-el deber de conservarla y darle vida a través del tiempo, por todos lados y para siempre, incluso frente a la imposibilidad. Sin salirnos del contexto cinematográfico, la experiencia del Mayo Francés tiene que ver con hacer explotar todas esas dicotomías ya señaladas entre el poder y el contrapoder que los jóvenes argentinos vivieron por parte del brazo del Estado. También posibilita entender aquellas acciones juveniles configuradas hacia aquello que se nos presenta sistemáticamente en la cotidianeidad: aspirar a transformar la realidad como una forma de la transgresión a los ojos del Estado. Hacer política sin estar atravesados por ese propósito, es hacer de la política un simple ejercicio de administración. Y eso no es del todo malo (que haya administradores, que haya un orden), pero ese orden formal también necesita que no termine siendo solo una burocratización de lo existente y olvide que, en el fondo, toda ética y toda política que tenga como objetivo la apertura y la transformación de las condiciones de vida del otro — débil o carente - no sirve de mucho. Es precisamente esto lo que rompieron los movimientos de jóvenes al instalar un descontento de las condiciones existentes que ya presentaban como únicas las estructuras de poder existentes.

También se puede concluir que las concepciones del poder en Luhmann y Poulantzas no están alejadas y la película permitió una mirada hacia otros conceptos como el de Estado donde, por ejemplo, en el sociólogo alemán se liga a su teoría de sistemas (la cual acapara al Estado), mientras en el filósofo franco-griego, con fuerza de la teoría marxista, también está claramente vinculado al Estado. Por el lado de Luhmann, como el resultado de una interacción de comunicaciones entre sistemas, donde las diferentes formas de poder interactúan entre sí; y, por el lado de Poulantzas, como el resultado de la fragmentación de unos poderes hegemónicos dentro de los cuales el Estado es uno de ellos. Entonces ahí convergen, en la fragmentación.

Finalmente, la película deja múltiples preguntas: ¿cómo entender los problemas relacionados con el poder y el Estado en el pasado, pero aún vigentes en la cotidianidad?, ¿qué sucede con la separación y fragmentación de las esferas públicas y privadas para el establecimiento del poder, su ejercicio y la emergencia del contrapoder y la resistencia?, ¿está esto en concordancia con las clases sociales que plantea Marx? 


\section{Referencias}

Arratia, A. (2010). Dictaduras latinoamericanas. Revista Venezolana de Análisis de Coyuntura, $X V I(1), 33-51$.

Bourdieu, P. (1996). Espíritu de Estado: génesis y estructura del campo burocrático. Revista Sociedad, (96), 49-62.

Bourdieu, P. (2000). Cosas dichas. Gedisa.

Castells, M. (2008). Comunicación, poder y contrapoder en la sociedad en red (II). Los nuevos espacios para la comunicación. Telos: Cuadernos de Comunicación e Innovación, (75), 11-23.

Castells, M. (2013). Comunicación y poder. Siglo XXI.

Chul-Han, B. (2018). Poder. Herder.

Cohn-Bendit, D. (2008). Forget 68. Seuil.

De Moraes, D., Ramonet, P., \& Serrano, P. (2014). Medios, poder y contrapoder: de la concentración monopólica a la democratización de la información. Biblos.

Derrida, J. (2001). Une certaine possibilité impossible de dire l'événement. En J. Derrida, A. Nouss, \& G. Soussana (Eds.), Dire l'événement, est-ce possible? Séminare de Montréal, pour Jacques Derrida. L'Harmattan.

Di Napoli, P. (2013). Pensar las ciencias sociales desde Gramsci y Bourdieu: dos propuestas que se encuentran [Ponencia]. X Jornadas de Sociología. Buenos Aires, Argentina.

Educación y Memoria. (2001). Noche de los lápices. https://bit.ly/3fKKmH 4

Estefanía, J. (2018). Revoluciones: cincuenta años de rebeldía (1968-2018). Galaxia Gutenberg.

Glucksman, A., \& Glucksman, R. (2018). Mayo del 68: por la subversión permanente. Penguin Random House.

González-Arana, R., \& Molinares-Guerrero, I. (2012). Movimiento obrero y protesta social en Colombia, 1920-1950. Historia Caribe, 8(22), 167-193.

Gramsci, A. (2008). Materialismo histórico, filosófico y política moderna. Comares.

Grimmson, A., \& Bidaseca, K. (2013). Hegemonía cultural y políticas de la diferencia. Clacso.

Heidegger, M. (2005). ¿Qué es metafísica? Siglo Veinte.

Korstanje, E. (2010). Reseña de Poder de Niklas Luhmann. Revista Austral de Ciencias Sociales, (18), 131-135. https://doi.org/10.4206/rev.austral.cienc.soc.2010.n18-08

Laurent, V. (2009). Mayo del 68, 40 años después: entre herencias y controversias. Revista de Estudios Sociales, (33), 29-43. https://doi.org/10.7440/res33.2009.02

Le Goff, J. P. (2006). Mai 68, l'héritage impossible. La Découverte. 
Luhmann, N. (2005). Poder. Anthropos.

Luhmann, N. (2015). La realidad de los medios. Anthropos.

Mestman, M., Oubiña, D., Sanjinés, J., Xavier, J., Pinto., Becerra, S., García.Borrero, J. A., Vásquez-Mantecón, A., Lacruz, C., Ortega, M. L., Varela, M., \& Halperin, P. (2016). Las rupturas del 68 en el cine de América Latina. Akal.

Meyer, J. (2008). El movimiento estudiantil en América Latina. Sociológica (México), 23(68), $179-195$.

Noguera-Fernández, A. (2011). La teoría del Estado y del poder en Antonio Gramsci: claves para descifrar la dicotomía dominación-liberación. Nómadas. Critical Journal of Social and Juridical Sciences, 29(1), 1-21. https://doi.org/10.5209/rev_noma.2011.v29.n1.26799

Olivera, H. (Director). (1986). La noche de los lápices [Film]. Aries Cinematográfica.

Parra-Valencia, L., Aponte-Muñoz, A. C., \& Dueñas-Manrique, M. M. (2018). Jóvenes, grupo y arte: las personas jóvenes y el arte re-unidos. Revista Latinoamericana de Ciencias Sociales, Niñez y Juventud, 16(2), 853-865. https://doi.org/fnxs

Peralta-Duque, B. del C. (2016). La participación juvenil en la política pública de juventud, 1997-2011 (Caldas, Colombia). Revista Latinoamericana de Ciencias Sociales, Niñez y Juventud, $14(2), 1249-1272$.

Pöggeler, O. (1993). El camino del pensar de Martin. Alianza.

Poulantzas, N. (1975). La crisis de las dictaduras: Portugal, Grecia, España. Siglo XXI.

Poulantzas, N. (1978). Estado, poder y socialismo. Siglo XXI.

Poulantzas, N. (1982). Hegemonía y dominación en el Estado moderno. Siglo XXI.

Poulantzas, N. (1985). Introducción al estudio de la hegemonía en el Estado: hegemonía y dominación en el Estado moderno. Siglo XXI.

Raggio, S. M. (2011). Los relatos de La noche de los Lápices: modos de narrar el pasado reciente. Aletheia, $1(2), 1-8$.

Reato, C. (2018, 19 de mayo). Jorge Rafael Videla: un dictador en formol que confesó atrocidades en el Libro maldito. Infobae. https://bit.ly/3cQKogz

Rotman, P. (2008). Mai 68 raconté à ceux qui ne l'ont pas vécu. Seuil.

Saldarriaga, J. (2011). Cine y ciencia política. Unaula. 